\title{
Apolipoprotein E e4 allele influences aggressive behaviour in Alzheimer's disease
}

\author{
D Craig, D J Hart, K McCool, S P Mcllroy, A P Passmore
}

J Neurol Neurosurg Psychiatry 2004;75:1327-1330. doi: 10.1136/jnnp.2003.032276

The rising number of people with cognitive impairment is placing health care budgets under significant strain. Dementia related behavioural change is a major independent risk factor for admission to expensive institutional care, and aggressive symptoms in particular are poorly tolerated by carers and frequently precipitate the collapse of home coping strategies. Aggressive change may result from known genetic risk factors for Alzheimer's disease (AD) and therefore accompany conventional markers such as apolipoprotein $\mathrm{E}(\mathrm{ApoE})$. We tested this hypothesis in 400 moderately to severely affected $A D$ patients who were phenotyped for the presence of aggressive or agitated behaviour during the month prior to interview using the Neuropsychiatric Inventory with Caregiver Distress. The proportion of subjects with aggression/agitation in the month prior to interview was $51.8 \%$. A significantly higher frequency of the e4 allele was found in individuals recording aggression/agitation in the month prior to interview $\left(\chi^{2}=6.69, d f=2, p=0.03\right)$. The additional risk for aggression/agitation conferred by e4 was also noted when e4 genotypes were compared against non-e4 genotypes $\left(\chi^{2}=5.45, d f=1, p=0.02, O R=1.60\right.$, confidence interval (CI) 1.06 to 2.43 ). These results indicate that advanced Alzheimer's disease patients are at greater risk of aggressive symptoms because of a genetic weakness in apolipoprotein E.

B y 2050, individuals over the age of 60 years are likely to make up about $30 \%$ of the population in developed countries. ${ }^{1}$ The number of people with cognitive impairment is rising in the same way and the next 30 years will see an anticipated threefold increase in Alzheimer's disease (AD) sufferers in the US alone. ${ }^{2}$ These changes are likely to put healthcare budgets under significant strain, especially with regard to the provision of nursing care. ${ }^{3}$ Half of all patients diagnosed will need help with personal care, and one third will eventually be institutionalised. ${ }^{45}$

Intensive research into the pathophysiology of dementia has failed to identify disease modifying therapeutic agents; however, greater understanding of the components of dementia that finally necessitate admission to residential or nursing home care is also very necessary. Older dementia sufferers living alone, or those with greater functional disability seem more at risk. ${ }^{6}$ Carer provision and coping skills are also important. ${ }^{8-10}$ Other factors such as incontinence or falls will also influence the need for increased supervision and assistance. ${ }^{11} 12$

Dementia related behavioural change is a major independent risk factor for admission to institutional care. ${ }^{13}$ Each 1 point increase in the Neuropsychiatric Inventory (NPI) behaviour rating scale costs up to US\$400 per year in additional healthcare expense. ${ }^{14}$ Aggressive symptoms are common in Alzheimer's disease, are poorly tolerated by carers, and directly contribute to the need for institutionalisation. ${ }^{15}{ }^{16}$ Aggressive behaviours are persistent and affect one fifth to half of all patients in cross sectional surveys. ${ }^{17} 18$ They arise more commonly in middle and late phases of the clinical process and correlate with disease severity. ${ }^{17} 19$

It has been suggested that some behaviours result from known genetic risk factors for $\mathrm{AD}$. If this were the case, behavioural symptoms would be seen to accompany conventional markers such as apolipoprotein $\mathrm{E}$ (ApoE). The role of ApoE alleles in the aetiology of depression in dementia has been largely negative, ${ }^{20-26}$ although it may be wrong to attempt to connect the depressive phenotype that appears relatively early in the dementing process with traditional risk factors for $\mathrm{AD}$. If $\mathrm{AD}$ related risk factors do mediate behavioural change then perhaps analysis should be directed at behaviours such as aggression and psychosis, which emerge after a prolonged period of neurodegeneration. The relationship between ApoE and risk of psychosis in $\mathrm{AD}$ has been mixed, ${ }^{27-32}$ and the relationship between aggression and ApoE has been examined only in the context of mild to moderately demented AD patients. ${ }^{20} 28$

ApoE e4 confers considerable risk for $\mathrm{AD}$ and is associated with more rapid progression and greater cortical amyloid burden, ${ }^{33-37}$ therefore good theoretical reasons exist for linking ApoE to the emergence of the aggressive phenotype that appears later in the clinical course.

We tested this hypothesis in a large cohort of advanced AD patients who were phenotyped for the presence of aggressive or agitated behaviour during the month prior to interview using the NPI with Caregiver Distress (NPI-D) scale, a validated tool for this research. ${ }^{38}$

\section{METHODS}

Ethical approval was obtained from the research ethics committee of Queen's University, Belfast. Informed written consent was obtained from next of kin, and where possible, from patients. Subjects were identified from outpatient memory clinic records based at the Belfast City Hospital Trust, Mater Infirmorum, and Holywell Hospital. Patients fulfilled the National Institute of Neurological and Communicative Disorders and Stroke and the Alzheimer's Disease and Related Disorders Association (NINCDSADRDA) criteria for probable Alzheimer's disease. ${ }^{39}$ Only patients with a carer who had contact at least 3 days a week for at least 3 years were included, to ensure reliability of data.

Abbreviations: $A D$, Alzheimer's disease; ApoE, apolipoprotein $E$ (ApoE); FAST, Functional Assessment Staging; MMSE, Mini Mental State Examination; NINCDS-ADRDA, National Institute of Neurological and Communicative Disorders and Stroke and the Alzheimer's Disease and Related Disorders Association; NPI-D, Neuropsychiatric Inventory with Caregiver Distress; SPECT, single photon emission computed tomography 
The subjects and main carer were interviewed by means of the Mini Mental State Examination (MMSE), ${ }^{40}$ the NPI-D, ${ }^{38}$ and Functional Assessment Staging (FAST) ${ }^{41}$ Carers were asked for information on family history, personal history of psychiatric illness, and current/previous use of antipsychotic agents or cholinesterase inhibitors.

Genomic DNA was extracted from peripheral blood leukocytes by the salting out method. ${ }^{42}$ ApoE genotyping was performed essentially as described.$^{43}$ Genotype and allele frequencies were compared by $\chi^{2}$ analysis, which was also used to test whether the genotype frequencies deviated from the expected Hardy-Weinberg equilibrium. The level of statistical significance was set at $p=0.05$. The extent of any interaction with previous psychiatric history and previous/ current drug use was assessed using a multiple logistic regression model.

\section{RESULTS}

The mean (SD) age of participants was 78 (7.5) years, and $65.3 \%$ of the 400 participants were female. The average (SD) duration of illness at the point of sampling was 67.9 (41.2) months, and MMSE was 13.1/30 (9.2). The proportion of subjects with aggression/agitation in the month prior to interview was $51.8 \%$. The proportion of participants' recording prior or current use of antipsychotic agents and cholinesterase inhibitors was $9.5 \%$ and $62.8 \%$ respectively. The relationship between genotypes and alleles of ApoE and baseline variables is shown in table 1 . The distribution of genotypes following exclusion of the minor ApoE alleles did not differ significantly from that predicted by the HardyWeinberg equilibrium $\left(\chi^{2}=0.12, \mathrm{df}=1, \mathrm{p}=0.72\right.$ when aggression/agitation was present and $\chi^{2}=0.11, \mathrm{df}=1$, $\mathrm{p}=0.724$ when aggression/agitation was absent).

A significantly higher frequency of the e4 allele was found in individuals recording aggression/agitation in the month prior to interview (table 2). The additional risk for aggression/ agitation conferred by e 4 was also noted when e 4 containing genotypes were compared against non-e4 containing genotypes ( table 2). Comparison of mean ages in those individuals without aggression/agitation and those with aggression/ agitation of recent onset (within and including 24 months duration) were as follows: without aggression/agitation: mean age 78.8 (s.d. 7.4); with aggression/agitation: mean age 76.43 (s.d. 7.3). These differences were significant $(\mathrm{t}=2.77, \mathrm{df}=294, \mathrm{p}=0.006)$.

\section{DISCUSSION}

Over half our subjects showed aggression/agitation in the month prior to interview, thus confirming the frequent nature of these distressing symptoms, which act to raise the likelihood of carer breakdown and requirement for supervision and institutionalisation. ${ }^{15}{ }^{16}$ This report, in common
Table 2 The ApoE genotype and allele frequencies for $400 \mathrm{AD}$ patients with and without aggression/agitation

\begin{tabular}{|c|c|c|c|c|}
\hline \multirow[b]{3}{*}{ Genotype/allele } & \multicolumn{4}{|c|}{ Aggression/agitation } \\
\hline & \multicolumn{2}{|c|}{ Present } & \multicolumn{2}{|c|}{ Absent } \\
\hline & No. & $\%$ & No. & $\%$ \\
\hline e2/e2* & 2 & 1.0 & 3 & 1.6 \\
\hline e2/e3* & 4 & 2.0 & 9 & 4.7 \\
\hline e2/e4* & 8 & 3.8 & 5 & 2.6 \\
\hline e3/e3* & 76 & 36.5 & 86 & 44.7 \\
\hline e3/e4* & 89 & 42.8 & 72 & 37.5 \\
\hline $\begin{array}{l}\mathrm{e} 4 / \mathrm{e} 4^{*} \\
{ }^{*} \chi^{2}=7.73, d f=5, p=0.17\end{array}$ & 29 & 13.9 & 17 & 8.9 \\
\hline $\mathrm{e} 2 \dagger$ & 16 & 3.8 & 20 & 5.2 \\
\hline e3t & 245 & 58.9 & 253 & 65.9 \\
\hline $\mathrm{e} 4 \dagger$ & 155 & 37.3 & 111 & 28.9 \\
\hline $\begin{array}{l}\dagger \chi^{2}=6.69, d f=2, p=0.03 \\
\text { e2/e2+e2/e3+e3/e3 } \neq \\
\text { e2/e4+e3/e4+e4/e4 } \\
\ddagger \chi^{2}=5.45, d f=1 p=0.02,\end{array}$ & $\begin{array}{r}82 \\
126 \\
O R=\end{array}$ & $\begin{array}{r}39.4 \\
60.6 \\
60, \mathrm{Cl} 1\end{array}$ & $\begin{array}{c}98 \\
94 \\
\text { to } 2.43\end{array}$ & $\begin{array}{l}51.0 \\
48.0\end{array}$ \\
\hline
\end{tabular}

with all analyses of this type, is limited by the reliability of the carer completing the NPI questionnaire, which operates retrospectively. However, it can be reasonably assumed, given the distressing nature of the symptoms, that carers are unlikely to forget the transition to aggressive or agitated behaviour. Reliability was further improved by excluding patients unable to provide a reliable carer for interview.

To our knowledge, this is the first report to show an increased risk for aggressive/agitated behaviour in advanced $\mathrm{AD}$ patients possessing the ApoE e4 allele $(\mathrm{OR}=1.60$, CI 1.06 to 2.43). Previous negative results may be explained on the basis of sampling error in mild to moderate AD patients. ${ }^{20} 28$ ApoE is an accepted risk factor for $\mathrm{AD}$ and serves to lower the age of onset. ${ }^{33}$ ApoE is associated with more rapid progression as measured by single photon emission computed tomography (SPECT) and higher tangle burden in the brain. ${ }^{35-37} 44$ The accepted spread of neuropathological damage seen in $\mathrm{AD}$, from the hippocampus to frontal-temporalparietal regions, may encourage the development of those behavioural symptoms that not only localise regionally within the brain but are dependent on progressive neuronal loss and amyloid deposition away from the mesial temporal lobe. Frontal involvement is the best neuroanatomical correlate for aggression and agitation with secondary disruption of the serotonergic and dopaminergic systems. ${ }^{45-48}$ High agitation scores correlate with bilateral orbitofrontal and left anterior cingulated tangle burden, ${ }^{45}$ and with left frontotemporal hypoperfusion on SPECT scanning. ${ }^{46}$ While overall MMSE scores were similarly low between ApoE genotypes (mean 13.1/30) in our study, the MMSE has little

Table 1 Baseline characteristics according to apoE status

\begin{tabular}{|c|c|c|c|c|c|c|}
\hline & \multicolumn{6}{|c|}{ Genotype } \\
\hline & $2 / 2$ & $2 / 3$ & $2 / 4$ & $3 / 3$ & $3 / 4$ & $4 / 4$ \\
\hline Number & 5 & 13 & 13 & 162 & 160 & 46 \\
\hline Female (\%) & 60.0 & 53.8 & 92.3 & 63.0 & 67.7 & 60.9 \\
\hline Age (years) & 75.4 & 79.2 & 78.0 & 78.4 & 78.2 & 75.3 \\
\hline Duration/illness & 75.6 & 110.3 & 81.1 & 63.6 & 68.9 & 62.5 \\
\hline MMSE (/30) & 13.6 & 12.7 & 7.7 & 12.6 & 13.3 & 15.3 \\
\hline Positive FHx (\%) & 0 & 23.1 & 25.0 & 15.4 & 18.2 & 24.4 \\
\hline Prior psych $\mathrm{Hx}(\%)$ & 0 & 7.7 & 23.1 & 9.3 & 8.7 & 10.9 \\
\hline Prior or current use of & & & & & & \\
\hline $\begin{array}{l}\text { Cholinesterase } \\
\text { inhibitor }\end{array}$ & 80.0 & 46.2 & 45.5 & 62.1 & 62.9 & 71.7 \\
\hline Antipsychotic agents & 60.0 & 23.1 & 63.6 & 33.1 & 29.7 & 20.0 \\
\hline
\end{tabular}


capacity to detect deficits in frontal lobe functioning. Importantly, the mean age of subjects with recent aggressive problems (and therefore less at risk of reporter bias) was significantly lower than the mean age of individuals without reported aggression, thus lending support to the theory that accelerated AD pathology resulting from ApoE e4 inheritance secondarily precipitates behavioural problems such as aggression.

There may be other relevant genetic modalities inducing aggression. Increased risk of aggression in individuals in possession of particular dopamine receptor and serotonin promoter polymorphisms was reported, without examination of the potentially crucial confounding influence of ApoE. ${ }^{49-52}$ Investigating genetic risk factors for behavioural symptoms in dementia without accounting for the influence of ApoE is flawed as subclinical features may only become clinically relevant once a required period of neurodegeneration, mediated at least in part by ApoE, occurs.

Neuropsychiatric symptoms of dementia are burdensome for the patient and carer and expensive for healthcare systems. Given the therapeutic opportunity to target noncognitive decline through improved understanding of ApoE neurobiology, ${ }^{53}$ confirmation of these results is required in a longitudinal cohort followed until the late phase of $\mathrm{AD}$.

\section{ACKNOWLEDGEMENTS}

Supported by an Alzheimer's Disease Society 3 year project grant (S P McIlroy, A P Passmore) and a British Geriatric Society Senior Registrar startup grant (D Craig).

\section{Authors' affiliations}

D Craig, D J Hart, K McCool, S P Mcllroy, A P Passmore, Department of Geriatric Medicine, Queen's University of Belfast, Whitla Medical Building, 97 Lisburn Road, Belfast, UK

Competing interests: none declared

Correspondence to: Dr D Craig, Department of Geriatric Medicine, Queen's University of Belfast, Whitla Medical Building, 97 Lisburn Road, Belfast BT9 7BL, UK; david.craig@qub.ac.uk

Received 11 November 2003

Revised 16 December 2003

Accepted 19 December 2003

\section{REFERENCES}

1 De Santis G. Population Ageing in industrialized countries: challenges and issues. IUSSP Policy and Research Papers, 2001.http://www.iussp.org/ Publications on site/PRP/prp19.pdf.

2 Hebert LE, Scherr PA, Bienias JL, et al. Alzheimer disease in the US population: prevalence estimates using the 2000 census. Arch Neurol 2003:60:1119-22.

3 Andersen CK, Lauridsen J, Andersen K, et al. Cost of dementia: impact of disease progression estimated in longitudinal data. Scand J Public Health 2003;31:119-25.

4 Eaker ED, Vierkant RA, Mickel SF. Predictors of nursing home admission and/or death in incident Alzheimer's disease and other dementia cases compared to controls: a population-based study. J Clin Epidemiol 2002; 55:462-8

5 Matthews FE, Dening T. UK Medical Research Council Cognitive Function and Ageing Study. Prevalence of dementia in institutional care. Lancet 2002;360:225-6.

6 Smith GE, Kokmen E, O'Brien PC. Risk factors for nursing home placement in a population-based dementia cohort. J Am Geriatr Soc 2000;48:519-25.

7 Bianchetti A, Scuratti A, Zanetti O, Binetti G, Frisoni GB, Magni E, et al. Predictors of mortality and institutionalization in Alzheimer disease patients year after discharge from an Alzheimer dementia unit. Dementia 1995;6: 108-12.

8 Fisher L, Lieberman MA. A longitudinal study of predictors of nursing home placement for patients with dementia: the contribution of family characteristics. Gerontologist 1999;39:677-86.

9 Baumgarten M, Battista RN, Infante-Rivard C, et al. The psychological and physical health of family members caring for an elderly person with dementia. $J$ Clin Epidemiol 1992;45:61-70.

10 Burns A. The burden of Alzheimer's disease. Int J Neuropsychopharmacol 2000;3:31-38.
11 Thom DH, Haan MN, Van Den Eeden SK. Medically recognized urinary incontinence and risks of hospitalization, nursing home admission and mortality. J Am Geriatr Soc 1993;41:1083-9.

12 Andrieu S, Reynish E, Nourhashemi F, et al. Predictive factors of acute hospitalization in 134 patients with Alzheimer's disease: a one year prospective study. Int J Geriatr Psychiatry 2002;17:422-6.

13 Steele C, Rovner B, Chase GA, et al. Psychiatric symptoms and nursing home placement of patients with Alzheimer's disease. Am J Psychiatry, 1990;147, 1049-51.

14 Murman DL, Chen Q, Powell MC, Kuo SB, Bradley CJ, Colenda CC The incremental direct costs associated with behavioral symptoms in $A D$. Neurology 2002;59:1721-9

15 Nagaratnam N, Lewis-Jones M, Scott D, et al. Behavioral and psychiatric manifestations in dementia patients in a community: caregiver burden and outcome. Alzheimer Dis Assoc Disord 1998;12:330-4.

16 Levy ML, Cummings JL, Fairbanks LA, et al. Longitudinal assessment of symptoms of depression, agitation, and psychosis in 181 patients with Alzheimer's disease. Am J Psychiatry 1996;153:1438-43.

17 Lopez OL, Becker JT, Sweet RA, et al. Psychiatric symptoms vary with the severity of dementia in probable Alzheimer's disease. J Neuropsychiatry Clin Neurosci 2003;15:346-53.

18 Burns A, Jacoby R, Levy R. Psychiatric phenomena in Alzheimer's disease. IV: Disorders of behaviour, Br J Psychiatry 1990;157:86-94

19 Holtzer R, Tang MX, Devanand DP, et al. Psychopathological features in Alzheimer's disease: course and relationship with cognitive status. J Am Geriatr Soc 2003:51:953-60.

20 Levy ML, Cummings JL, Fairbanks LA, et al. Apolipoprotein E genotype and noncognitive symptoms in Alzheimer's disease. Biol Psychiatry 1999;45:422-5.

21 Harwood DG, Barker WW, Ownby RL, et al. Apolipoprotein-E (APO-E) genotype and symptoms of psychosis in Alzheimer's disease. Am J Geriatr Psychiatry 1999;7:119-23.

22 Muller-Thomsen T, Arlt S, Ganzer S, et al. Depression in Alzheimer's disease might be associated with apolipoprotein $\mathrm{E}$ epsilon 4 allele frequency in women but not in men. Dement Geriatr Cogn Disord 2002;4:59-63.

23 Holmes C, Russ C, Kirov G, et al. Apolipoprotein E: depressive illness, depressive symptoms, and Alzheimer's disease. Biol Psychiatry 1998;43:159-64.

24 Ballard C, Massey H, Lamb H, et al. Apolipoprotein E: non-cognitive symptoms and cognitive decline in late onset Alzheimer's disease. I Neurol Neurosurg Psychiatry 1997;63:273-4.

25 Lyketsos CG, Baker L, Warren A, et al. Depression, delusions, and hallucinations in Alzheimer's disease: no relationship to apolipoprotein $\mathrm{E}$ genotype. J Neuropsychiatry Clin Neurosci 1997;9:64-7.

26 Ramachandran G, Marder K, Tang M, et al. A preliminary study of apolipoprotein $\mathrm{E}$ genotype and psychiatric manifestations of Alzheimer's disease. Neurology 1996;47:256-9.

27 Lopez OL, Kamboh MI, Becker JT, et al. The apolipoprotein E epsilon 4 allele is not associated with psychiatric symptoms or extrapyramidal signs in probable Alzheimer's disease. Neurology 1997;49:794-7

28 Hirono N, Mori E, Yasuda M, et al. Factors associated with psychotic symptoms in Alzheimer's disease. J Neurol Neurosurg Psychiatry 1998:64:648-52

29 Cacabelos R, Rodriguez B, Carrera C, et al. Behavioral changes associated with different apolipoprotein E genotypes in dementia. Alzheimer Dis Assoc Disord 1997;11(Suppl 4):S27-34.

30 Forsell Y, Basun $\mathrm{H}$, Corder EH, et al. Psychotic symptoms and apolipoprotein E genotypes in an elderly population. Biol Psychiatry 1998;44:139-40.

31 Lehtovirta M, Soininen H, Helisalmi S, et al. Clinical and neuropsychological characteristics in familial and sporadic Alzheimer's disease: relation to apolipoprotein E polymorphism. Neurology 1996;46:413-19.

32 Sweet RA, Kamboh MI, Wisniewski SR, et al. Apolipoprotein E and alpha-1antichymotrypsin genotypes do not predict time to psychosis in Alzheimer's disease. J Geriatr Psychiatry Neurol 2002;15:24-30.

33 Corder EH, Saunders AM, Strittmatter WJ, et al. Gene dose of apolipoprotein E type 4 allele and the risk of Alzheimer's disease in late onset families. Science, 1993;261, 921-3.

34 Meyer MR, Tschanz JT, Norton MC, et al. APOE genotype predicts when-not whether-one is predisposed to develop Alzheimer disease. Nat Genet, 1998; 19, 321-2.

35 Kanai M, Shizuka M, Urakami K, et al. Apolipoprotein E4 accelerates dementia and increases cerebrospinal fluid tau levels in Alzheimer's disease. Neurosci Lett 1999;267:65-8.

36 Gomez-Isla T, West HL, William RG, et al. Clinical and pathological correlates of apolipoprotein E $\in 4$ in Alzheimer's disease. Ann Neurol, 1996;39, 62-70.

37 McNamara MJ, Gomez-Isla T, Hyman BT. Apolipoprotein E genotype and deposits of $A \beta 40$ and A $\beta 42$ in Alzheimer disease. Arch Neurol, 1998;55, 1001-4.

38 Kaufer DI, Cummings JL, Christine D, et al. Assessing the impact of neuropsychiatric symptoms in Alzheimer's disease: the Neuropsychiatric Inventory Caregiver Distress Scale. J Am Geriatr Soc 1998;46:210-15.

39 McKhann G, Drachman D, Folstein M, et al. Clinical diagnosis of Alzheimer's disease: report of the NINCDS-ADRDA Work Group under the auspices of Department of Health and Human Services Task Force on Alzheimer's Disease. Neurology 1984;34:939-44.

40 Folstein MF, Folstein SE, McHugh PR. "Mini-mental state". A practical method for grading the cognitive state of patients for the clinician. J Psychiatr Res 1975; 12:189-98.

41 Reisberg B. Functional assessment staging (FAST). Psychopharmacol Bull 1988;24:653-9. 
42 Miller SA, Dykes DD, Polesky HF. A simple salting out procedure for extracting DNA from human nucleated cells. Nucleic Acids Res 1988;16:1215.

43 Mcllroy SP, Crawford VL, Dynan KB, et al. Butyryllcholinesterase K variant is genetically associated with late onset Alzheimer's disease in Northern Ireland. J Med Genet 2000;37:182-5.

44 Lehtovirta M, Soininen H, Laakso MP, et al. SPECT and MRI analysis in Alzheimer's disease: relation to apolipoprotein E epsilon 4 allele. J Neurol Neurosurg Psychiatry 1996;60:644-9.

45 Tekin S, Mega MS, Masterman DM, et al. Orbitofrontal and anterior cingulate cortex neurofibrillary tangle burden is associated with agitation in Alzheimer disease. Ann Neurol 2001;49:355-61.

46 Hirono N, Mega MS, Dinov ID, et al. Left frontotemporal hypoperfusion is associated with aggression in patients with dementia. Arch Neurol 2000;57:861-6.

47 Lawlor B. Serotonin and Alzheimer's disease. Psychiatr Ann 1990;20:567-70.
48 Reinikainen KJ, Soininen $\mathrm{H}$, Reikkinen PJ. Neurotransmitter changes in Alzheimer's dementia and agitation. J Neurosci Res 1990;27:576-86.

49 Sukonick DL, Pollock BG, Sweet RA, et al. The 5-HTTPR*S/*L polymorphism and aggressive behavior in Alzheimer disease. Arch Neurol 2001;58:1425-8.

50 Sweet RA, Pollock BG, Sukonick DL, et al. The 5-HTTPR polymorphism confers liability to a combined phenotype of psychotic and aggressive behavior in Alzheimer disease. Int Psychogeriatr 2001;13:401-9.

51 Holmes C, Smith H, Ganderton R, et al. Psychosis and aggression in Alzheimer's disease: the effect of dopamine receptor gene variation. I Neurol Neurosurg Psychiatry 2001;71:777-9.

52 Sweet RA, Nimgaonkar VL, Kamboh MI, et al. Dopamine receptor genetic variation, psychosis, and aggression in Alzheimer disease. Arch Neurol 1998:55:1335-40.

53 Marques MA, Crutcher KA. Apolipoprotein E-related neurotoxicity as a therapeutic target for Alzheimer's disease. J Mol Neurosci 2003;20:327-37. 